Document downloaded from:

http://hdl.handle.net/10251/39732

This paper must be cited as:

Leyva Perez, A.; Oliver Meseguer, J.; Cabrero Antonino, JR.; Rubio Marqués, P.; Serna, P.; Al-Resayes, SI.; Corma Canós, A. (2013). Reactivity of Electron-Deficient Alkynes on Gold Nanoparticles. ACS Catalysis. 3(8):1865-1873. doi:10.1021/cs400362c.

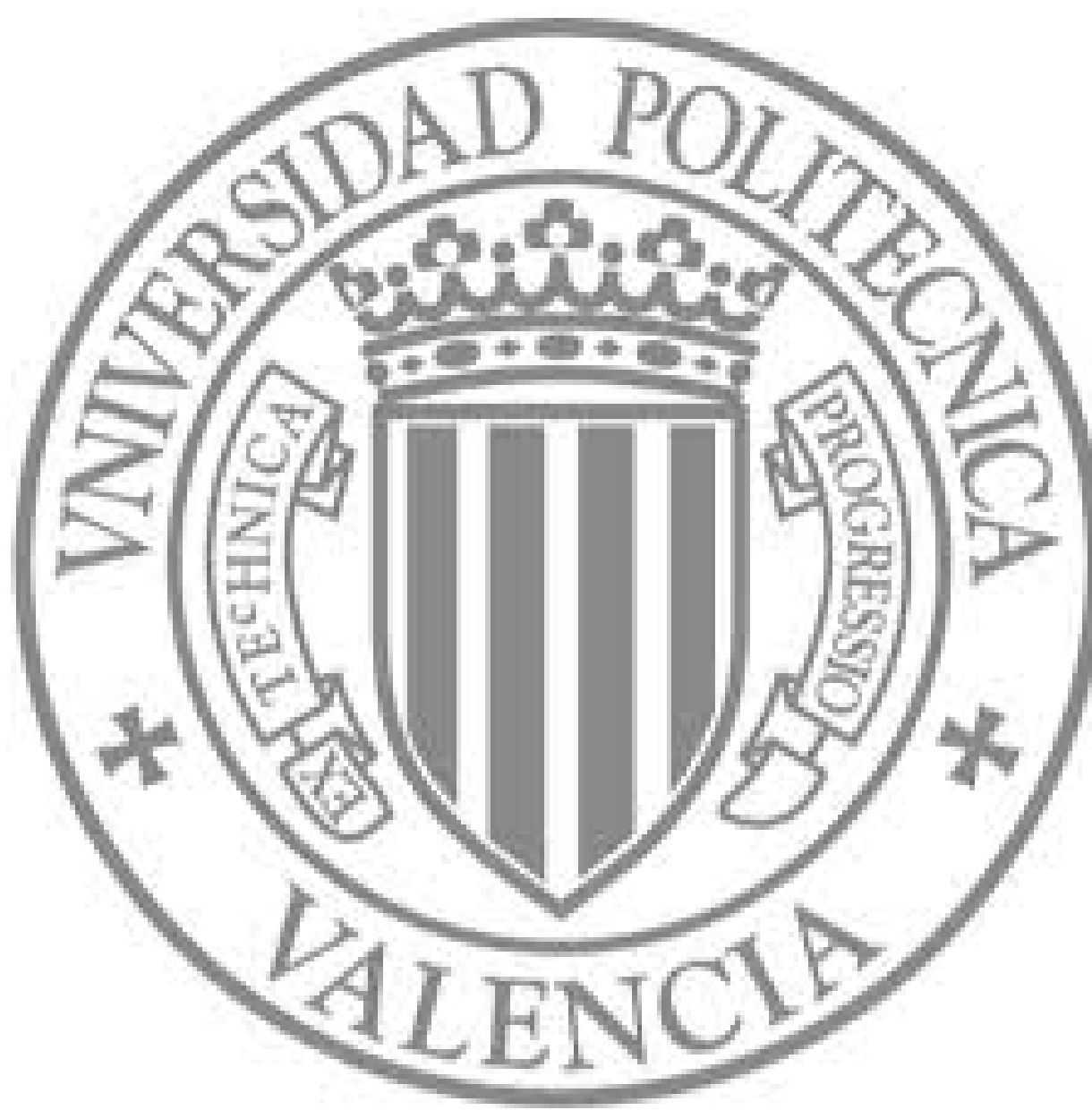

The final publication is available at

http://dx.doi.org/10.1021/cs400362c

Copyright American Chemical Society 


\section{Reactivity of electron-deficient alkynes on gold}

\section{nanoparticles.}

Antonio Leyva-Pérez, ${ }^{a}$ Judit Oliver-Meseguer, ${ }^{a}$ Jose R. Cabrero-Antonino, ${ }^{a}$ Paula RubioMarqués, ${ }^{a}$ Pedro Serna,${ }^{a}$ Saud I. Al-Resayes,${ }^{b}$ and Avelino Corma. ${ }^{a, b} *$

${ }^{\text {a }}$ Instituto de Tecnología Química. Universidad Politécnica de Valencia-Consejo Superior de Investigaciones Científicas. Avda. de los Naranjos s/n, 46022, Valencia, Spain.

${ }^{\mathrm{b}}$ Chemistry Department, College of Science, King Saud University B.O. BOX.2455 Riyadh 11451 Saudi Arabia.

KEYWORDS. Gold catalysis, supported nanoparticles, oxidative alkynylation of arenes, cyclotrimerization, $\mathrm{C}-\mathrm{H}$ activation.

ABSTRACT. Propiolates cyclotrimerize in the presence of catalytic amounts of gold nanoparticles to give aryl benzoates in high yields and with turnover frequencies of thousands per hour. Other types of alkynes rather than propiolates do not react and, if molecular oxygen is present and dissociated by the gold nanoparticles, electron-rich arenes engage with the propiolate to form a new $\mathrm{C}-\mathrm{C}$ bond. The activation of propiolates and electron-rich arenes to form $\mathrm{C}-\mathrm{C}$ bonds, beyond gold-catalyzed Michael additions, constitutes a new example of how and where gold nanoparticles modify the electronic density of unsaturated C-C bonds and opens the door to future transformations. 


\section{Introduction}

Gold catalysis has become a trending topic in current research due to the continuous discovery of new transformations and unexpected reaction pathways. ${ }^{1-3}$ Different solid-supported and homogeneous gold catalysts have been reported, and although the latter allows a fine tuning of the electronic/steric properties of the metal through ligand interactions, the former is preferred by economical, practical, and environmental reasons. ${ }^{4-7}$ The electronic nature of gold nanoparticles as a function of size, shape, and interaction with the support has been studied for particular reactions and some structure-activity relationships (SARs) have been made ${ }^{8-10}$ though a complete switch of reactivity for a single molecule by fine-tuning the catalytic activity of the nanoparticle is rarely presented. In this regard, the use of additives on the nanoparticle to reach a better reactivity control can offer new opportunities. ${ }^{11}$ As illustrated in Scheme 1, we will show that a) propiolates react selectively on gold nanoparticles to form aryl rings, b) electron-rich arenes seem to enhance the cyclotrimerization, and c) both molecules finally engage if the gold nanoparticle is partially oxidized with molecular oxygen.

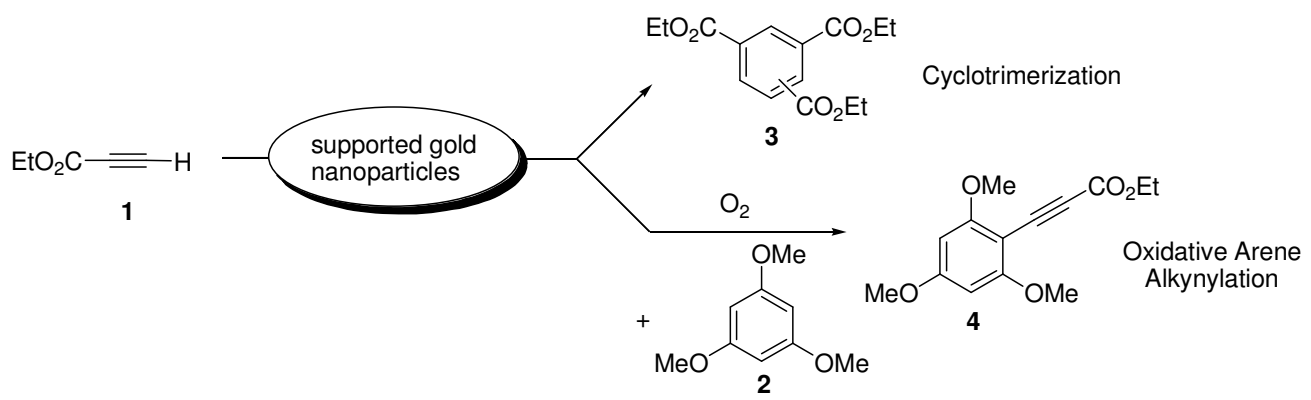

Scheme 1. Different reaction pathways for ethyl propiolate 1 on supported gold nanoparticles. 


\section{Results and Discussion}

\section{- Nature of the gold catalyst.}

If ethyl propiolate $\mathbf{1}$ is heated with a catalytic amount of $\mathrm{Au}-\mathrm{TiO}_{2}$ in 1,2-dichlorobenzene under air, the cyclotrimerization reaction occurs in good yields and selectivity, as shown in Figure $1 .^{12,13}$ The reaction rate is not improved in nitrogen atmosphere and no reaction occurs in the presence of other gold-supported catalysts such as $\mathrm{Au}-\mathrm{CeO}_{2}, \mathrm{Au}-\mathrm{Fe}_{2} \mathrm{O}_{3}, \mathrm{Au}-\mathrm{Al}_{2} \mathrm{O}_{3}$ or $\mathrm{Au}-$ carbon, and very little with $\mathrm{Au}-\mathrm{ZnO}$ (see Supporting Information, Table S1, entries 6-10) under these reaction conditions. A sample of $\mathrm{Au}-\mathrm{TiO}_{2}$ was further reduced with phenylethanol under nitrogen atmosphere and tested in-situ for the cyclotrimerization of $\mathbf{1}$, and no catalytic differences were found when compared with the $\mathrm{H}_{2}$-reduced sample (Figure S1). ${ }^{13}$ With $\mathrm{Au}(\mathrm{I}$ ) chloride as a catalyst only minor amounts of product were obtained after prolonged times, and $\mathrm{Au}(\mathrm{III})$ salts were completely inactive for the cyclotrimerization (entries 11-12 in Table S1). A literature search showed that there is only one precedent for the gold-catalyzed cyclotrimerization of alkynes. ${ }^{14}$ There, trisalkynegold(I) complexes decomposes into cyclotrimerization products after heating in a hexane/dichloromethane (DCM) mixture, and a catalytic amount of $\mathrm{AuSbF}_{6}$ is also able to accomplish the cyclotrimerization of the raw alkyne, but in both cases the yields are $<50 \%$. 

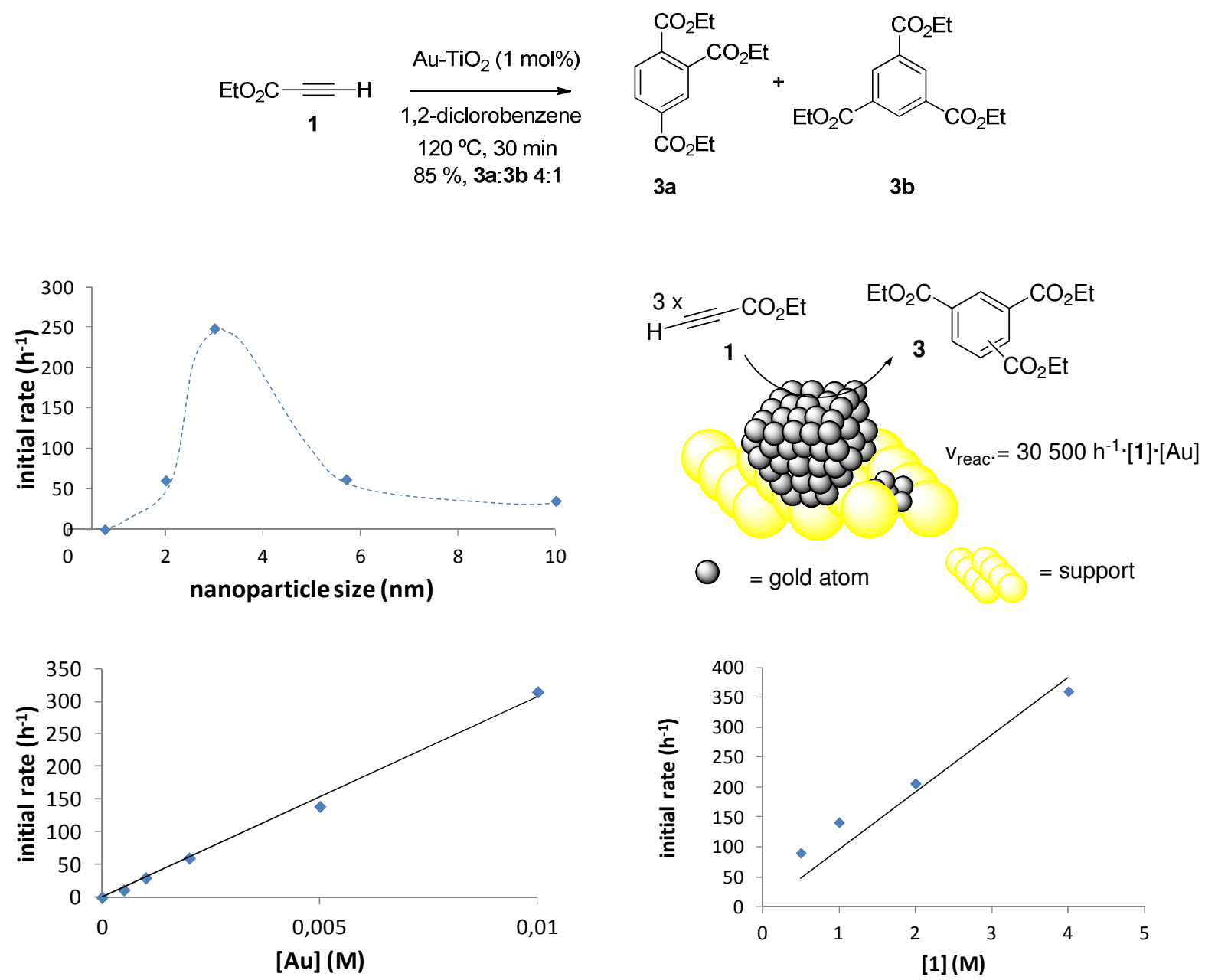

Figure 1. Top: $\mathrm{Au}-\mathrm{TiO}_{2}$-catalyzed cyclotrimerization of $\mathbf{1}$. Reaction conditions: 1 ( $25.3 \mu \mathrm{l}, 0.25$ mmol), Au-TiO 2 (1 wt $\%, 45 \mathrm{mg}, 1 \mathrm{~mol} \%)$, 1,2-dichlorobenzene (0.5 ml, $0.5 \mathrm{M})$. Mass balances $>95 \%$, not other by-products found. Middle: Initial rate for the cyclotrimerization of $\mathbf{1}$ as a function of the crystal size for samples containing 1.0-1.5 wt $\%$ of $\mathrm{Au}$ on $\mathrm{TiO}_{2}$ (left) and schematic drawing on the mechanism including the calculated equation rate (right). Bottom: Initial rate for the cyclotrimerization of $\mathbf{1}$ as a function of the concentration of $\mathrm{Au}-\mathrm{TiO}_{2}$ catalyst (left) and alkyne 1 (right). Dodecane was used as an external standard. 
A solvent screening showed that only alkyl hydrocarbons or chlorinated compounds are good solvents for the reaction while coordinating solvents such as dioxane, toluene or ethyl acetate inhibit the reaction (Table S2). These observations connect with the feasibility of the reaction in hexane/DCM mixtures after decomposition of gold(I) complexes, ${ }^{14}$ and reflects that gold nanoparticles present a high sensitivity to external coordinating groups when activating alkyne $\mathbf{1}$ for the cyclotrimerization reaction.

If the higher catalytic activity found for gold on titania compared to ceria comes from a more pronounced metallic character of gold on the former support, as assessed by X-Ray Photoelectron Spectroscopy (XPS, Figure S2), gold nanoparticles with metallic character should catalyze the cyclotrimerization reaction independently of the support employed. This was confirmed after fully reducing a sample of $\mathrm{Au}-\mathrm{CeO}_{2}$ with phenylethanol in order to generate a more metallic gold (Figure S2), and the catalytic performance of this reduced Au-CeO $\mathrm{Sample}_{2}$ increased for the cyclotrimerization of $\mathbf{1}$ respect to that of hydrogen-reduced $\mathrm{Au}-\mathrm{CeO}_{2}$ (Table $\mathrm{S} 1$, entry 13). On the other hand, gold subnanoparticles $(<1 \mathrm{~nm})$ are quasi-molecular species with tendency to stabilize positive charges, thus accordingly they should be inactive for the reaction. When a sample of $\mathrm{Au}-\mathrm{TiO}_{2}$ was treated with methyl iodide, ${ }^{15}$ the Diffuse Reflectance Ultraviolet-Visible (DR-UV-Vis) spectrum (Figure S3) showed that only small gold clusters remain on the solid and that the plasmonic gold nanoparticles are absent. When this sample of $<0.75 \mathrm{~nm}$ gold particle size was submitted to reaction conditions no cyclotrimerization occurred, suggesting the catalytic activity of metallic gold nanoparticles. 
With these results in hand, we have to accept that the catalytic activity for the cyclotrimerization of $\mathbf{1}$ is related with electron-rich $\mathrm{Au}^{0}$ crystals, and it could very well occur that there is an optimum size of the gold nanoparticle for catalyzing the trimerization reaction. To check this, we prepared and tested different $\mathrm{Au}-\mathrm{TiO}_{2}$ solids with particle sizes ranging from $<1$ to $\sim 10 \mathrm{~nm}^{16,17}$ and Figure 1 shows that the initial catalytic activity peaks at gold nanoparticles of $\sim 3 \mathrm{~nm}$ and levels off for shorter and larger crystallite sizes. These results indicate that the surface gold atoms on the nanoparticles facilitate the reaction and that crystallites of $3 \mathrm{~nm}$ suppose a good compromise between atoms exposed and metallic nature.

\section{- Reaction mechanism.}

The accepted general mechanism for the cyclotrimerization of alkynes involves the formation of a five-membered organometallic ring that inserts a third alkyne unit to finally collapse into the benzene ring and regenerating the catalyst. ${ }^{[18-26 a]}$ However, in the case of gold nanoparticles, these crowded organometallic rings are very improbable since gold prefers mono- or biscoordinated linear structures. Therefore, we may think on an alternative mechanism. For doing that, we decomposed the global reaction process into the elementary steps of the reaction (Figure S4). It is clear that, depending on which is the controlling step, a different kinetic equation could be written. For instance, if the activation of the first alkyne molecule is the rate-limiting step (see Figure 1) then the rate equation will involve the concentration of the alkyne and gold, and a linear correlation between the initial reaction rate and the initial concentration of the alkyne and gold should be observed. Results in Figure 1 show that this is indeed what occurs, confirming that the first step is the rate-limiting. The calculated kinetic rate constant indicates that $\sim 30000$ catalytic cycles per hour are made in a $1 \mathrm{M}$ solution of gold and alkyne. Dodecane was used as an external standard during the catalytic experiments. 
To shed more light on the mechanism, deuterated ethyl propiolate $1-\boldsymbol{d}^{\boldsymbol{I}}$ was prepared ${ }^{27 \mathrm{a}}$ and used as substrate. The results (also in Figure S4) showed a kinetic isotopic effect (Kie) of 4.2. The observed Kie denotes that the terminal $\mathrm{C}-\mathrm{H}$ bond is somehow broken during the catalytic cycle and, together with the kinetic equation, gives a possible mechanism for the cyclotrimerization reaction in where the rate-determining step would consist in the $\sigma$-activation of $\mathbf{1}$ on gold, joining a second molecule of alkyne to finally cyclize with the third unit, as shown in Figure 2. In accordance with this rate equation, none of the intermediates were detected during reaction, indicating that the attack to the second alkyne and the final trimerization are much faster than the rate of activation of the first alkyne molecule.

Since the metallic gold atoms present an electron unpairing $6 s^{1}$ configuration that gives a possibility to radical catalysis, ${ }^{18}$ the radical inhibitor di-tert-butylcatechol was introduced in the reaction medium in order to check if the cyclotrimerization on gold is a radical reaction, and the results in Figure 2 show that the reaction was indeed inhibited, which confirms that radical intermediates are present during the catalytic cycle. ${ }^{27 \mathrm{~b}}$

It is not surprising that nanosized gold with metallic character catalyzes the cyclotrimerization of alkynes since other metals reported as catalysts for this reaction lie in low-oxidation states. ${ }^{19-26}$ In many cases, arene-type ligands have been employed as electron-donors to stabilize the metal charge. ${ }^{19 b, 22-24}$ We added electron-rich arenes in the reaction medium to test a possible enhancement of the cyclotrimerization reaction and the results in Figure 2 show that $\mathrm{Au}$ supported-solids become in general more active for the cyclotrimerization of $\mathbf{1}$ in the presence of methoxy-substituted arenes. It was also found that this catalytic enhancement is maximized for catalytic amounts of the arene (Figure S5) and decreases as the arene additive becomes less 
electron-rich, and finally a complete inhibition of the reaction occurs for neutral arenes such as mesitylene.
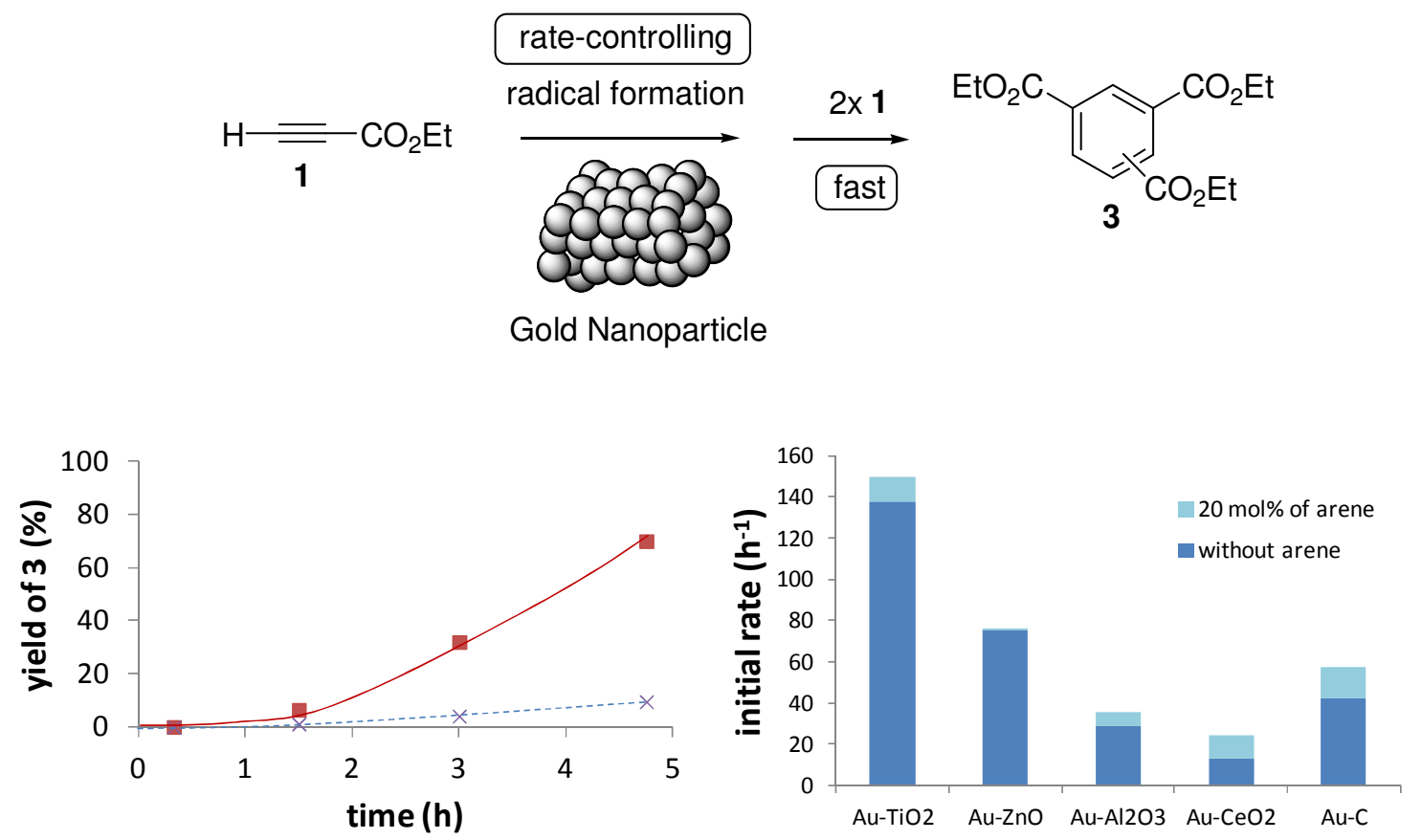

Figure 2. Top: Possible mechanism for the gold-catalyzed cyclotrimerization reaction. Bottom left: $\mathrm{Au}-\mathrm{CeO}_{2}$-catalyzed cyclotrimerization of $\mathbf{1}$ in the presence $(\times)$ or not $(\square)$ of $50 \mathrm{~mol} \%$ of ditert-butylcatechol. Bottom right: Initial rate for the Au-supported-catalyzed cyclotrimerization of $\mathbf{1}$ in the presence or not of $20 \mathrm{~mol} \%$ of 1,3,5-trimethoxybenzene 2. Reaction conditions: 1 (67.4 $\mu 1,0.66 \mathrm{mmol})$, catalyst $(0.5 \mathrm{~mol} \%), 1,2$-dichlorobenzene $(0.66 \mathrm{ml}, 1 \mathrm{M}), 120^{\circ} \mathrm{C}$. Dodecane was used as an external standard.

- Carbon-Carbon bond forming reaction. 
In view that ethyl propiolate $\mathbf{1}$ and 1,3,5-trimethoxybenzene $\mathbf{2}$ are probably co-adsorbed onto gold nanoparticles, we considered the possibility that both could be engaged in C-C bond forming reactions. In one hand, He and Shi have reported that aromatic rings and propiolates give Michael-type additions after $\mathrm{C}-\mathrm{H}$ activation of the ring in gold-catalyzed homogeneous conditions. ${ }^{28}$ In the other hand, Nevado and de Haro have recently reported that gold phosphine complexes catalyze the oxidative alkynylation of electron-rich rings in solution through $\mathrm{Au}(\mathrm{I}) /(\mathrm{III})$ redox cycles after treatment with strong iodine oxidants and base. ${ }^{29}$ Since it has been reported that gold nanoparticles dissociate molecular oxygen on unsaturated atoms to form oxygen reactive species (ORS), ${ }^{30}$ it was envisaged that the oxidative alkynylation of the arene may occur on the gold nanoparticle provided that gold could act as a bifunctional catalyst that activates the organic molecules and molecular oxygen at the same time. The ORS released after oxygen dissociation would act as the base needed to quench the protons generated during the reaction. If this was so, it would represent, to our knowledge, the first example of a homogeneous reaction catalyzed by $\mathrm{Au}(\mathrm{I}) / \mathrm{Au}(\mathrm{III})$ redox cycles that is also catalyzed by a gold heterogeneous system. ${ }^{31}$ The result in Scheme 2 shows that the oxidative propiolation of 2 to give 4 indeed occurs in reasonable yields with Au-carbon as a catalyst, after optimization (see also Table S3), and that the Michael-type addition reaction does not compete. Minor amounts of product 6, coming from either the oxidative cleavage of the triple bond or a hydration/retroaldolic sequence in $\mathbf{4}$, were observed in some cases.

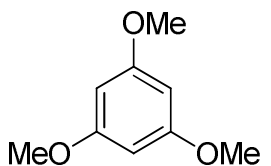

2

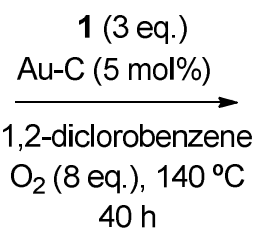

$40 \mathrm{~h}$

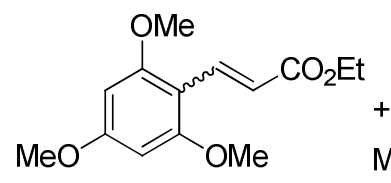

5, $8 \%$

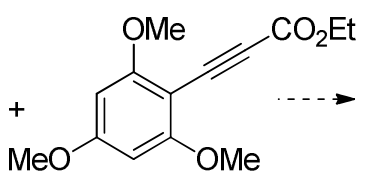

$4,58 \%$

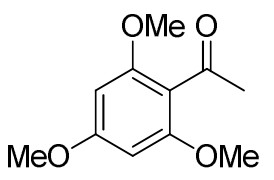

$6,3 \%$ 
Scheme 2. Results for the reaction between trimethoxybenzene $\mathbf{2}$ and ethyl propiolate $\mathbf{1}$ in the presence of $\mathrm{Au}-\mathrm{C}(5 \mathrm{~mol} \%)$ and molecular oxygen. Reaction conditions: 2 (21.0 mg, 0.125 mmol), 1 (38.0 $\mu \mathrm{l}, 0.375 \mathrm{mmol})$, 1,2-dichlorobenzene (0.5 ml). Percentages refer to GC yields. Complete mass balance for the arene and $\sim 80-99 \%$ for the alkyne. Reaction stops after $\mathbf{1}$ is transformed into 3 (not shown).

Experiments with $\mathrm{AuCl}$ and $\mathrm{HAuCl}_{4}$ (Table S3, entries 1-2) showed that, as expected, ${ }^{28}$ the Lewis-catalyzed Michael addition to form $\mathbf{5}$ occurs in moderate yields with neat cationic gold, and cationic gold stabilized on $\mathrm{CeO}_{2}$ and $\mathrm{Fe}_{2} \mathrm{O}_{3}$ also gave the addition product $\mathbf{5}$ preferentially to 4 (entries 5-7). These results confirm that the unsaturated gold atoms on the nanoparticles, having a cationic character, catalyze the Michael-type addition, as salts do. To check this, a new experiment was performed in the absence of oxygen (entry 12) and no product 4 was found but only $\mathbf{5}$ and 3, which confirms that the oxidative alkynylation only occurs under the action of oxygen and that, otherwise, the Michael-type addition proceeds on the cationic gold present. In order to further check that the oxidative coupling product $\mathbf{4}$ does not come from the Michael product, the cinnamylic ester 5 was prepared independently ${ }^{28}$ and introduced under oxidative conditions. No reaction was observed in that case. With these results in hand, in principle, cationic supported gold remains aside of the oxidative process. Oxygen dissociation on small gold nanoparticles has been proved elsewhere ${ }^{31}$ and electrovoltammetry of the Au-carbon solid confirmed the feasibility of the redox process. ${ }^{32-33}$

Deuterated ethyl propiolate $1-\boldsymbol{d}^{\mathbf{I}}$ was prepared and Scheme 3 shows that the oxidative alkynylation is inhibited when used as a reactant, only Michael addition occurring. Notice that 1- 
$\boldsymbol{d}^{I}$ also retards the cyclotrimerization reaction (kie observed) and these results suggest that the deprotonation of the propiolate occurs before the oxidative coupling. If this is so, the cyclotrimerization should compete with the alkynylation and this is indeed observed (see Table S3). The results would explain the moderate conversion of arene 2 since propiolate consumption occurs even in high excess.
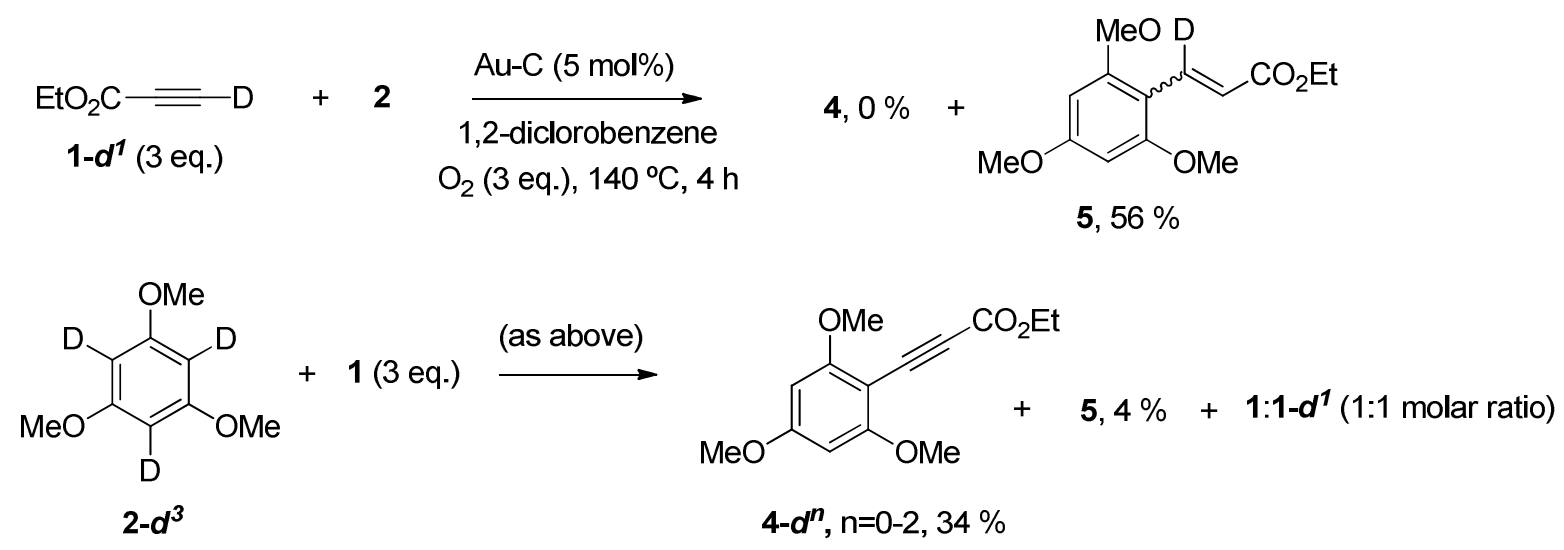

Scheme 3. Isotopic experiments for the oxidative alkynylation between trimethoxybenzene 2 and ethyl propiolate $\mathbf{1}$ in the presence of gold-supported nanoparticles and molecular oxygen.

Trimethoxybenzene $\mathbf{2 - d ^ { 3 }}$ was also prepared and tested in reaction, and Scheme 3 shows that hydrogen-exchange was also observed, even in the absence of the gold catalyst. Deuterium scrambling between $\mathbf{2}-\boldsymbol{d}^{3}$ and $\mathbf{1}$ confirms somehow the interaction of the arene with gold. Nevertheless, none of these two processes are the rate-limiting step of the reaction since the Hexchange rate is much faster than the coupling rate (seven times faster for the arene), so it must be assumed that the final coupling constitutes the rate-limiting step. 
A tentative mechanism for the alkynylation of trimethoxybenzene $\mathbf{2}$ on Au-carbon is depicted in Scheme 4. The different steps proposed are supported by kinetic, isotopic, and spectroscopic experiments. Overall, small gold nanoparticles dissociate molecular oxygen, probably only in the presence of the reactants, to give basic ROS that neutralize the protons released by the alkyne and the arene after gold activation, and a final reductive elimination process engages both molecules into a new C-C bond and regenerates the metallic gold sites. This reaction pathway is in accordance with one proposed by Nevado and de Haro in solution. ${ }^{29}$

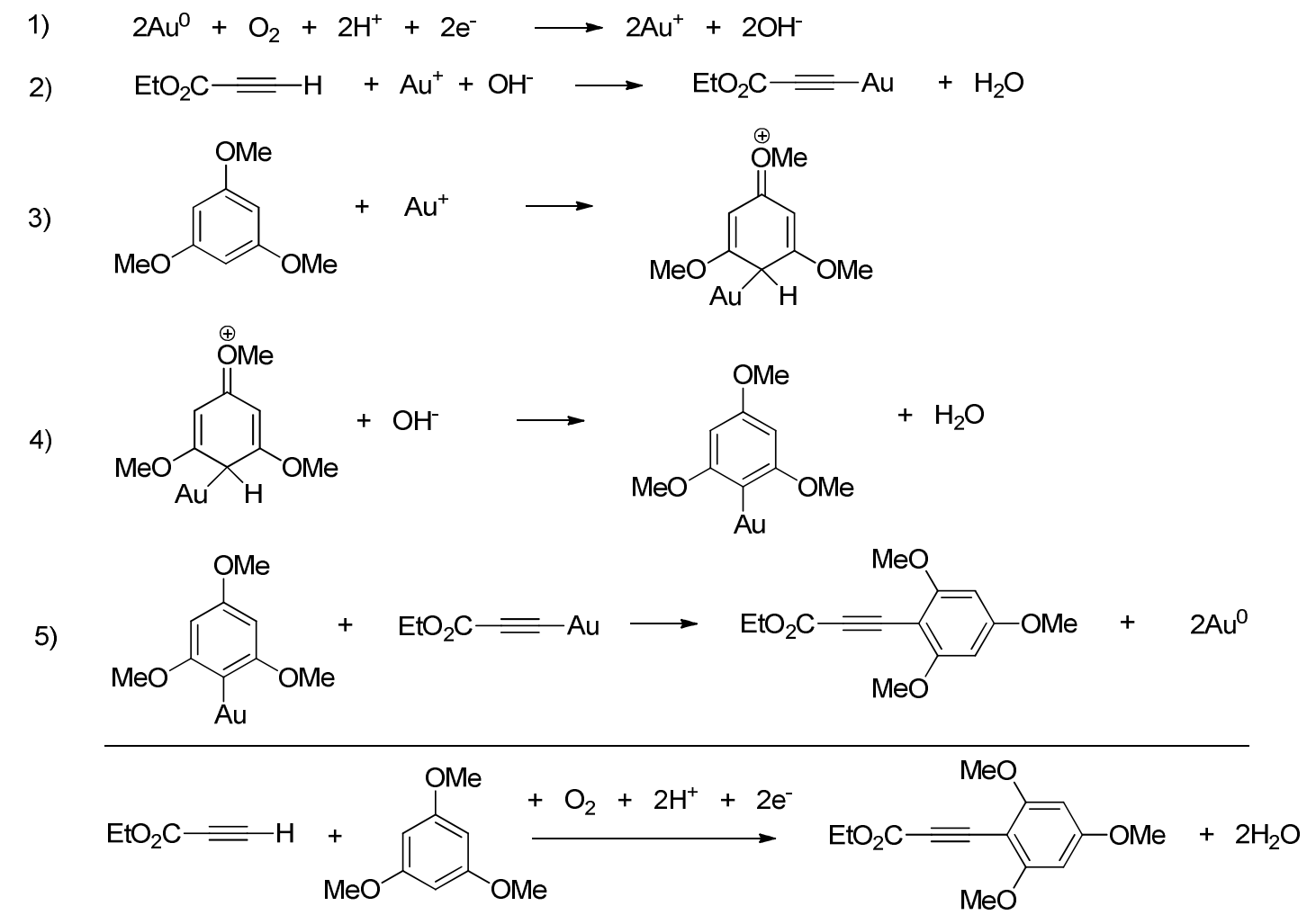

Scheme 4. Tentative mechanism for the oxidative alkynylation between trimethoxybenzene 2 and ethyl propiolate $\mathbf{1}$ in the presence of gold-supported nanoparticles and molecular oxygen. 
- Scope of the reactions.

Now it seems possible to control the reactivity of propiolates toward the cyclotrimerization reaction or the oxidative alkynylation of arenes by using the appropriate gold-supported nanoparticles under oxygen or not. A brief scope of the reactions was evaluated after preparing different propiolates $^{34}$ and the results in Figure 3 reveal that the propiolates engage intermolecularly with different diynes for the cyclotrimerization reaction and also with the arene 2 for the oxidative coupling in good yields. Remarkably, a Turn Over Number (TON) of 5000 can be obtained for the cyclotrimerization of $\mathbf{1}$ which constitutes, as far as we know, the highest recorded for an intermolecular cyclotrimerization of alkynes. 

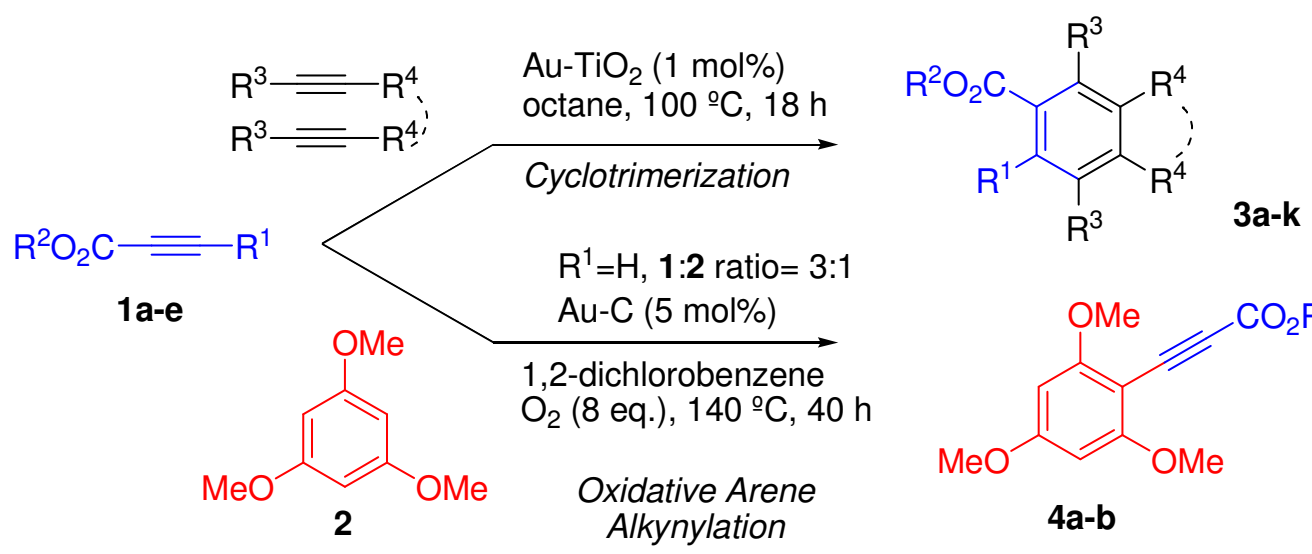

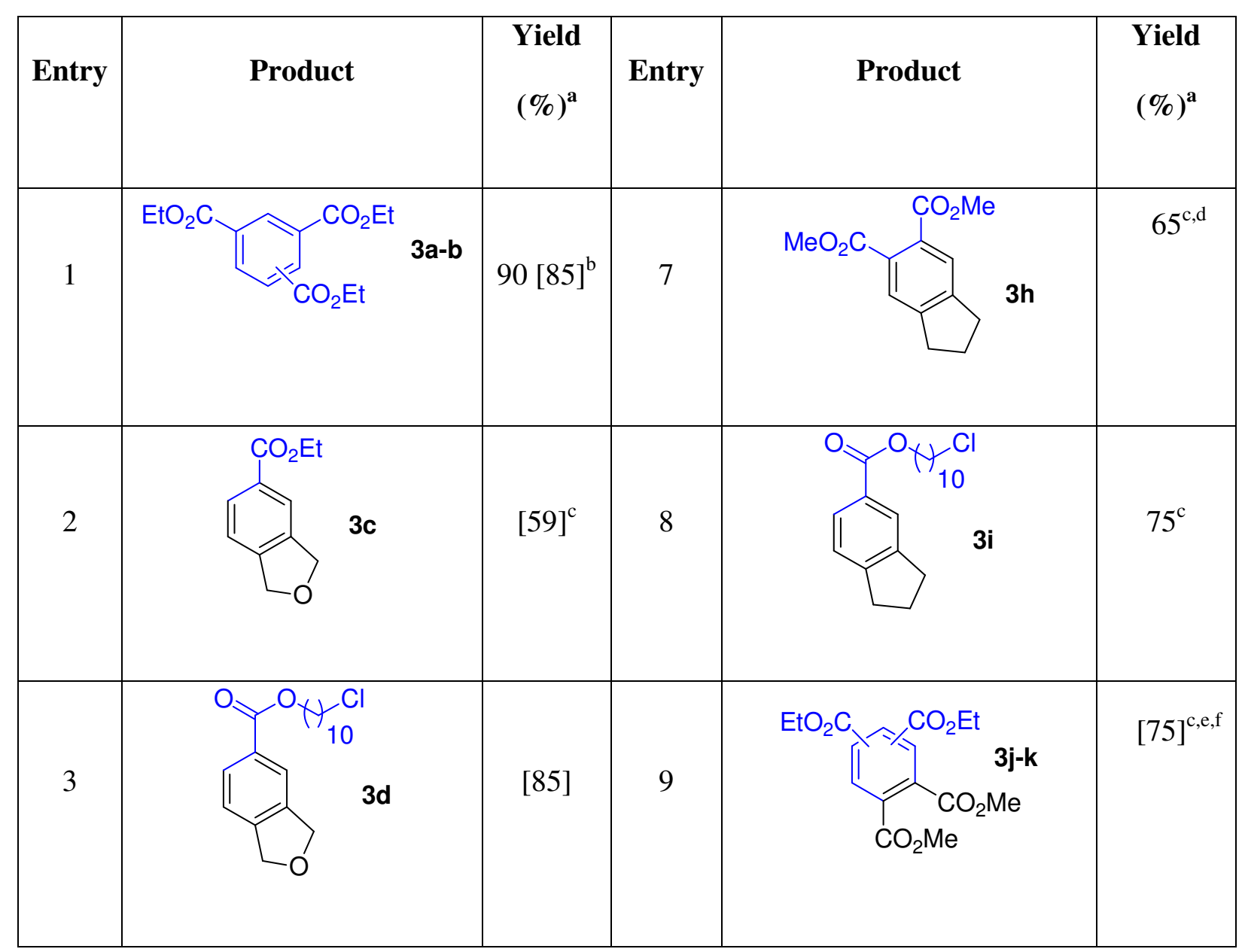




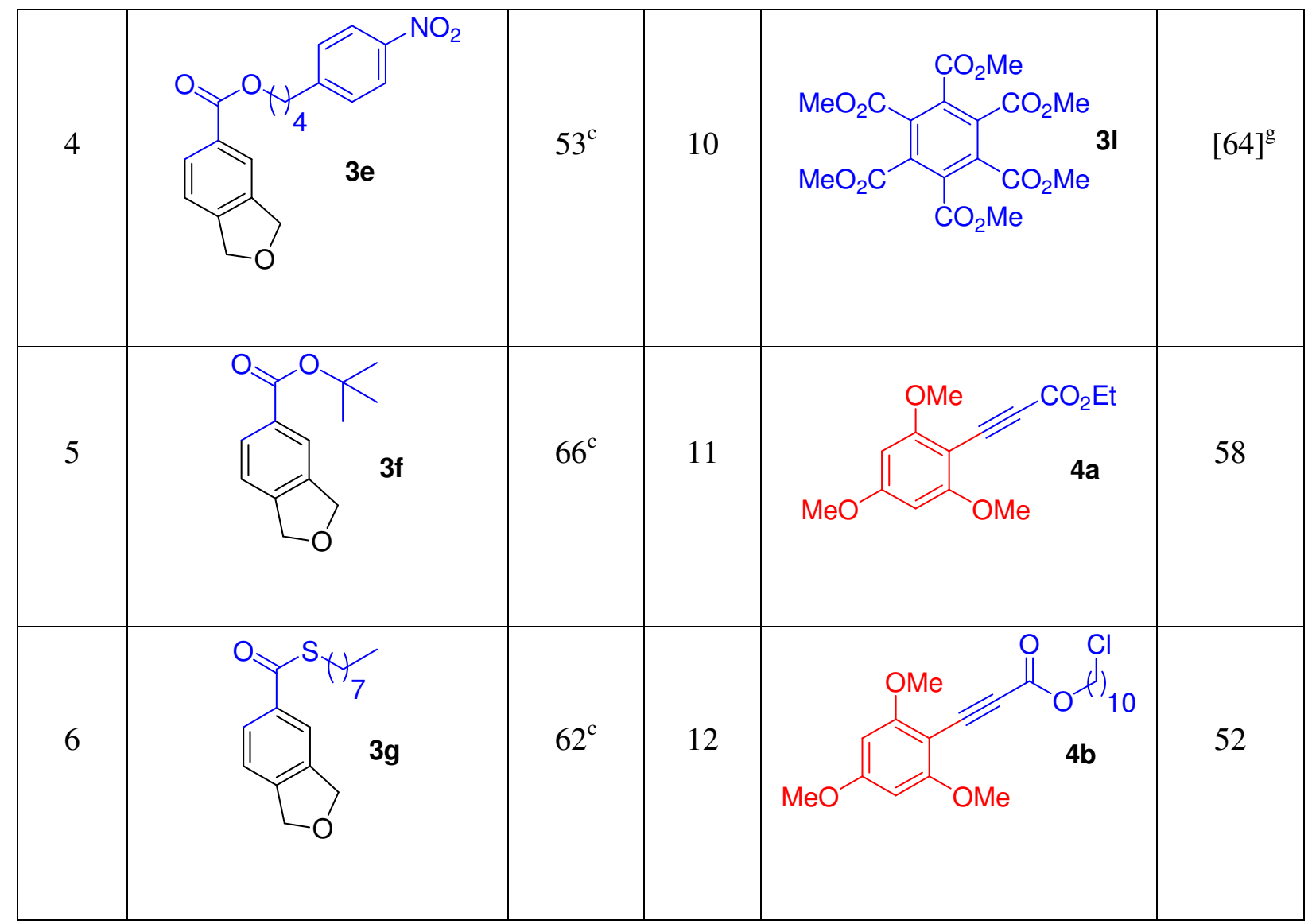

Figure 3. Scope for the cyclotrimerization and oxidative alkynylation of different propiolates 1ae and trimethoxybenzene $\mathbf{2}$ in the presence of gold-supported nanoparticles and oxygen. ${ }^{\mathrm{a}} \mathrm{GC}$ yields, between brackets isolated yields. ${ }^{\mathrm{b}}$ Ratio isomers 4:1; with $0.015 \mathrm{~mol} \% \mathrm{Au}, 77 \%$ yield, TON: 5000. ${ }^{\mathrm{c}} 3$ equivalents of propiolate. ${ }^{\mathrm{d}} 2 \mathrm{~mol} \%$ Au. ${ }^{\mathrm{e}} 5$ equivalents of $1 \mathrm{a} .{ }^{\mathrm{f}}$ Ratio isomers 1:1. ${ }^{\mathrm{g}}$ Reaction temperature $120^{\circ} \mathrm{C}$.

Different functionalities including ether, chloride, and nitro groups are tolerated under the reaction conditions. Dimethylacetylene dicarboxylate (DMAD) 1e reacts with other alkynes (3h, $\mathbf{3 j - k}$ ) and with itself (3l) when forcing the reaction conditions. The reactivity of internal alkynes strongly supports a radical mechanism. In any case, the cyclotrimerization does not proceed unless one of the partners is a propiolate. For instance, a benchmark substrate for the cyclotrimerization reaction $^{12}$ such as the entropic and sterically-favored tryine 7 was prepared ${ }^{35 a}$ 
and tested under $\mathrm{Au}-\mathrm{TiO}_{2}$ catalyzed conditions and the result in Scheme 5 shows that no reaction occurs. However, if the non reactive internal alkyne is converted in a propiolate such as triyne $\mathbf{8},{ }^{35 \mathrm{~b}}$ it does react with DMAD 1e to give the cyclotrimerization product $\mathbf{9}$ having a free, unreacted, terminal alkyne. Other common cyclotrimerization partners such as nitriles ${ }^{12}$ do not react either. These results illustrate the high specificity of $\mathrm{Au}-\mathrm{TiO}_{2}$ toward propiolates.

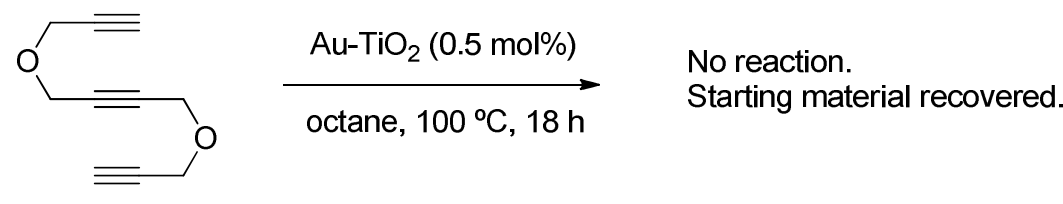

7

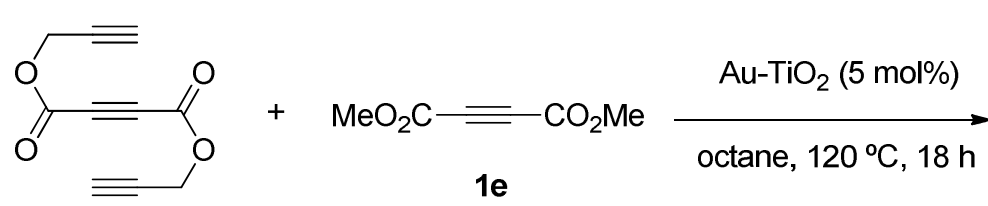

8<smiles>C#CCOC(=O)c1c2c(cc(C(OC)OC)c1C(=O)OC)COC2=O</smiles>

$9,40 \%$

Scheme 5. Failed cyclotrimerization reaction of tryine 7 (top) and selective intermolecular cyclotrimerization of $\mathbf{8}$ and $\mathbf{1 e}$ (bottom) under $\mathrm{Au}-\mathrm{TiO}_{2}$ catalyzed conditions. GC yields.

\section{- Catalyst stability and reusability.}

At this point, an extensive study on the reusability and stability of the catalyst under reaction conditions was carried out. As shown in Figure 4, $\mathrm{Au}-\mathrm{TiO}_{2}$ could be reused up to six times for the cyclotrimerization of $\mathbf{1}$ in $n$-decane after filtering the solid just at complete conversion (22 min) but a slight decrease in both the initial rate and final conversion was observed. 

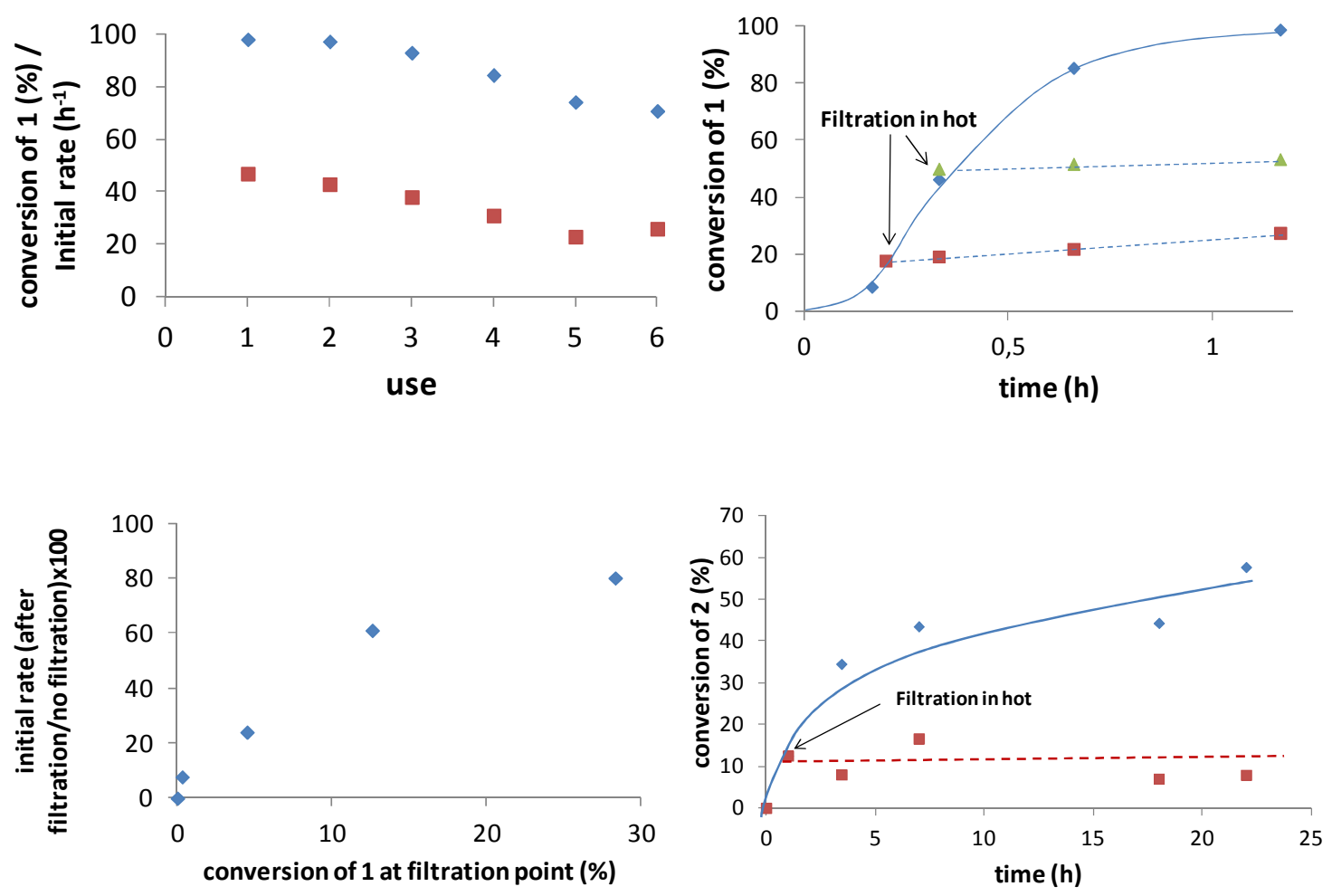

Figure 4. Top left: Reusability of $\mathrm{Au}-\mathrm{TiO}_{2}$ in the cyclotrimerization of $\mathbf{1}$, in terms of final yield $(\diamond)$ and initial rate $(\square)$. Top right: Hot filtration test for the cyclotrimerization of $\mathbf{1}$ by filtering at $20 \%(\square)$ and $50 \%(\Delta)$ conversion of $\mathbf{1}$. Bottom left: Percentage of contribution in the reaction rate for the cyclotrimerization of $\mathbf{1}$ of the leached species after filtration of $\mathrm{Au}-\mathrm{CeO}_{2} \cdot \mathrm{Au}-\mathrm{TiO}_{2}$ gave similar results. Bottom right: Hot filtration test by filtering at $10 \%$ ( $\square$ ) for the oxidative alkynylation of $\mathbf{1}$ and $\mathbf{2}$. Reaction conditions for the cyclotrimerization: $\mathbf{1}$ (67.4 $\mu 1,0.66 \mathrm{mmol}$ ), catalyst ( $1 \mathrm{~mol} \%$ left, $0.5 \mathrm{~mol} \%$ right $), n$-decane $(0.66 \mathrm{ml}, 1 \mathrm{M}), 120^{\circ} \mathrm{C}$. Reaction conditions for the oxidative alkynylation: $1(38.0 \mathrm{ml}, 0.375 \mathrm{mmol}), 2(21 \mathrm{mg}, 0.125 \mathrm{mmol}), 1,2-$ dichlorobenzene $(0.5 \mathrm{ml})$, catalyst $(5 \mathrm{~mol} \%), 120^{\circ} \mathrm{C}$, molecular oxygen (6 bar, $\sim 1 \mathrm{mmol}, \sim 8$ eq. $)$. Dodecane was used as an external standard. 
Hot filtration tests revealed that no active species are present in solution, but Inductive Coupled Plasma-Atomic Emission Spectroscopy analysis of the filtrates and X-Ray Fluorescence measurements of the reused solid showed that $\sim 5 \%$ of the total gold in the solid was leached to the solution during reaction, which explains the gradual loss of activity. After this result, the possible leaching and activity of gold species in 1,2-dichlorobenzene was scrutinized by filtering the solid at different times and comparing the initial rate before and after filtration. The results in Figure 4 show a progressive contribution of leached species to the catalytic activity, but this contribution is only significant at conversions of $\mathbf{1}>20 \%$, even at long reaction times, which denotes that the initial rate measurements reflect only catalytically-active supported gold species. The filtration hot test was also carried out for the oxidative alkynylation of $\mathbf{1}$ and $\mathbf{2}$ and revealed that no active species are present in solution with 1,2-dichlorobenzene as a solvent, which confirms that the catalytic process occurs onto the solid. The presence of inactive gold in solution during the reaction fits well with the lack of catalytic activity of uncoordinated atoms on the solid since the latter are easily leached into the solution. A similar effect has been observed for gold-catalyzed Sonogashira reactions. ${ }^{4 a-b}$

\section{Conclusions}

Propiolates give different reactions on supported gold nanoparticles depending on the nature of the particle and the amount of oxygen present: Cyclotrimerization products on metallic nanoparticles, Michael additions with 1,3,5-trimethoxybenzene on cationic gold species, and oxidative alkynylation of 1,3,5-trimethoxybenzene for terminal propiolates if enough molecular oxygen dissociates on the gold nanoparticle.

\section{Experimental Section}


Preparation of the solid catalysts. $\mathrm{Au}-\mathrm{TiO}_{2}{ }^{16,17}$ and $\mathrm{Au}-\mathrm{CeO}_{2}{ }^{4 \mathrm{a}, 6}$ solids were prepared according to a reported procedure. In some cases gold was incorporated onto the solids by the incipient wetness methodology with a solution of $\mathrm{AuCl}$ in acetonitrile, drying in an oven at 100 ${ }^{\circ} \mathrm{C}$ after impregnation and reducing under $\mathrm{H}_{2}$ at the specified temperature. XPS showed that no chlorides remain onto the solid after treatment under hydrogen at high temperature. Alternatively, neat phenylethanol (5 ml per gram of solid) was used as reducing agent in a preheated oil bath at $160{ }^{\circ} \mathrm{C}$ for $1 \mathrm{~h}$, washing with acetonitrile and diethyl ether and drying under vacuum. The commercial samples used were supplied by: Strem, Aurelite ${ }^{\mathrm{TM}}\left(\mathrm{Au}-\mathrm{TiO}_{2} 1 \mathrm{wt} \%\right.$, $\mathrm{Au}-\mathrm{ZnO}, 1$ wt \%, Au- $\left.\mathrm{Al}_{2} \mathrm{O}_{3} 1 \mathrm{wt} \%\right)$; and Johnson-Matthey, Au-CeO $\mathrm{C}_{2}(1 \mathrm{wt} \%)$ and Au-Carbon $(2.3$ wt $\%)$.

Preparation of propiolates. Ethyl (1a, referred for simplification as $\mathbf{1}$ throughout the text), tertbutyl (1d), and dimethyl (1e) were supplied by Aldrich. The chloro- and nitro-substituted ones were prepared according to a modified standard procedure ${ }^{34}$ as follows. Synthesis of functionalized terminal propiolates $\mathbf{1 b}$ and $\mathbf{1}$ : A mixture of DCC (2.32 g) and DMAP (0.090 g) in $\mathrm{DCM} / \mathrm{Et}_{2} \mathrm{O}(5 / 25 \mathrm{ml})$ was added dropwise over $20 \mathrm{~min}$ to a solution of the corresponding alcohol $(10.0 \mathrm{mmol})$ and propiolic acid $(0.678 \mathrm{ml}, 11.0 \mathrm{mmol})$ in $\mathrm{Et}_{2} \mathrm{O}(5 \mathrm{ml})$ at $-30{ }^{\circ} \mathrm{C}$. The reaction mixture was stirred overnight at room temperature, quenched with saturated $\mathrm{NH}_{4} \mathrm{Cl}(15$ $\mathrm{ml})$ and the aqueous layer was extracted with $\mathrm{Et}_{2} \mathrm{O}(3 \times 15 \mathrm{ml})$. The combined organic extracts were dried over magnesium sulfate, concentrated under reduced pressure and purified by column chromatography to give the corresponding terminal propiolate.

The triynes $\mathbf{7}$ and $\mathbf{8}$ were prepared according to reported procedures. ${ }^{35}$ 
Typical procedure for the cyclotrimerization of 1 . The solid catalyst ( $1 \mathrm{~mol} \%$ of metal respect to 1) was placed in a $2 \mathrm{ml}$ vial equipped with a magnetic stirrer. 1,2-Dichlorobenzene, $n$-decane or $n$-octane $(0.66 \mathrm{ml})$ and ethyl propiolate $1(67.6 \mu \mathrm{l}, 0.66 \mathrm{mmol})$ were added and the vial was sealed. The resulting mixture was placed in a pre-heated oil bath at $120{ }^{\circ} \mathrm{C}$ and magnetically stirred for the corresponding time. Aliquots were periodically taken, poured into diethyl ether or $\mathrm{CH}_{2} \mathrm{Cl}_{2}(1.0 \mathrm{ml})$, filtered through a $0.2 \mu \mathrm{m}$ PTFE filter syringe if needed and submitted to GC and GC-MS analysis after dodecane $(5.6 \mu \mathrm{l}, 0.05 \mathrm{mmol})$ was added as external standard. In some cases dodecane $(14.6 \mu \mathrm{l}, 0.066 \mathrm{mmol})$ was added to the reaction as internal standard. At the end of the reaction, diethyl ether or $\mathrm{CH}_{2} \mathrm{Cl}_{2}(1 \mathrm{ml})$ was added after cooling the vial and the mixture was stirred for a few minutes at room temperature, solids were filtered off and the resulting filtrates were analyzed as the aliquots. For reusing, $n$-decane $(1 \mathrm{ml})$ was used as a solvent and the solid was washed twice with decane $(1 \mathrm{ml})$ before the next run. The resulting solid after six uses was washed with $\mathrm{CH}_{2} \mathrm{Cl}_{2}$ (3 ml, 3 times) and dried under vacuum before analyses. Isolation of the products was performed by column chromatography or preparative TLC (15\% AcOEt/Hexane) to give $\mathbf{3}$ as a mixture of triethylbenzene-1,2,4-tricarboxylate (3a, major) and triethylbenzene-1,3,5-tricarboxylate $(\mathbf{3 b}$, minor) in a 4:1 ratio. The reaction could be scaled up to 5 mmol without loss of efficiency. Triethylbenzene-1,2,4-tricarboxylate 3a, colorless oil (40 mg, $60 \%$,). $\mathrm{R}_{\mathrm{f}}(20 \% \mathrm{AcOEt} / \mathrm{Hexane}):$ 0.42. GC/MS (m/z, M+2 294), major peaks found: 294 (11\%), $249(100 \%), 221(100 \%), 193(90 \%)$. IR $\left(\mathrm{cm}^{-1}\right): 2982,1727,1307,1283,1245,1110 .{ }^{1} \mathrm{H} \mathrm{NMR}$ $(\delta, \mathrm{ppm} ; J, \mathrm{~Hz}): 8.31(1 \mathrm{H}, \mathrm{dd}, J=1.6,0.5), 8.10(1 \mathrm{H}, \mathrm{dd}, J=8.1,1.6), 7.67(1 \mathrm{H}, \mathrm{dd}, J=8.0,0.5)$, $4.32(6 \mathrm{H}, \mathrm{q}, J=7.1), 1.32(9 \mathrm{H}, \mathrm{t}, J=7.1) .{ }^{13} \mathrm{C} \mathrm{NMR}(\delta, \mathrm{ppm}): 167.0(\mathrm{C}), 166.4(\mathrm{C}), 164.8(\mathrm{C})$, $136.1(\mathrm{C}), 132.5(\mathrm{C}), 132.0(\mathrm{C}), 131.9(\mathrm{CH}), 129.9(\mathrm{CH}), 128.7(\mathrm{CH}), 61.8\left(\mathrm{CH}_{2}\right), 61.7\left(\mathrm{CH}_{2}\right)$, $61.5\left(\mathrm{CH}_{2}\right), 14.1\left(\mathrm{CH}_{3}\right), 14.0\left(\mathrm{CH}_{3}\right), 13.9\left(\mathrm{CH}_{3}\right)$. HRMS (ESI) $\left[(\mathrm{M}+\mathrm{H})^{+}\right.$; calculated for $\mathrm{C}_{11} \mathrm{H}_{15} \mathrm{O}_{3}$ : 
195.1021] found $\mathrm{m} / \mathrm{z}$ 195.1014. Triethylbenzene-1,3,5-tricarboxylate $\mathbf{3 b}$, white solid (10 $\mathrm{mg}, 15$ $\%$,) $\mathrm{R}_{\mathrm{f}}(20 \%$ AcOEt/Hexane): 0.52. GC/MS (m/z, M+ 294), major peaks found: 294 (27\%), 266 (36 \%), 249 (100\%), 238, (24\%), 221 (66\%), 210 (26\%), 193 (31\%). IR (cm-1): 2996, 1726, 1718, 1239. ${ }^{1} \mathrm{H}$ NMR $(\delta, \mathrm{ppm} ; J, \mathrm{~Hz}): 8.77(3 \mathrm{H}, \mathrm{s}), 4.37(6 \mathrm{H}, \mathrm{q}, J=7.1), 1.36(9 \mathrm{H}, \mathrm{t}, J=7.1) .{ }^{13} \mathrm{C}$ NMR ( $\delta, \mathrm{ppm}): 165.0(\mathrm{Cx} 3), 134.4(\mathrm{CHx} 3), 131.4(\mathrm{Cx} 3), 61.7\left(\mathrm{CH}_{2} \mathrm{x} 3\right), 14.3\left(\mathrm{CH}_{3} \mathrm{x} 3\right) . \mathrm{HRMS}$ (ESI) $\left[(\mathrm{M}+\mathrm{H})^{+}\right.$; calculated for $\left.\mathrm{C}_{11} \mathrm{H}_{15} \mathrm{O}_{3}: 195.1021\right]$ found $m / z$ 195.1014.

Typical procedure for the oxidative alkynylation. The solid catalyst $(5 \mathrm{~mol} \%$ of metal respect to 2) and trimethoxybenzene $2(21 \mathrm{mg}, 0.125 \mathrm{mmol})$ were placed in a double-walled glass $2 \mathrm{ml}$ reactor equipped with a magnetic stirrer and a manometer. 1,2-Dichlorobenzene $(0.5 \mathrm{ml})$ and ethyl propiolate $1(38.0 \mu 1,0.375 \mathrm{mmol})$ were added and the reactor was closed. Molecular oxygen (6 bar, $\sim 0.9 \mathrm{mmol}$ ) was introduced at room temperature and the resulting mixture was magnetically stirred in a pre-heated oil bath at $120{ }^{\circ} \mathrm{C}$ for the required time. Aliquots were periodically taken, poured into $\mathrm{CH}_{2} \mathrm{Cl}_{2}(1 \mathrm{ml})$, filtered through a $0.2 \mu \mathrm{m}$ PTFE filter syringe and submitted to GC and GC-MS analysis after dodecane $(5.6 \mu 1,0.025 \mathrm{mmol})$ was added as an external standard. At the end of the reaction, $\mathrm{CH}_{2} \mathrm{Cl}_{2}(1 \mathrm{ml})$ was added after cooling the reactor and the mixture was stirred for a few minutes at room temperature, solids were filtered off and the resulting filtrates were analysed as the aliquots.

Hot filtration tests. Two parallel reaction mixtures were followed by GC, taking aliquots periodically, under typical reaction conditions and one of them was filtered in hot at a determined conversion through a $0.2 \mu \mathrm{m}$ PTFE filter. The resulting filtrates were placed under the same conditions (stirring and temperature) that the original reaction and also followed by GC. 


\section{ASSOCIATED CONTENT}

Supporting Information. General procedures, syntheses and characterization of catalysts, substrates and products, reaction procedures, additional tables and figures, and NMR copies of compounds. This material is available free of charge via the Internet at http://pubs.acs.org.

\section{AUTHOR INFORMATION}

\section{Corresponding Author}

Prof. A. Corma. E-mail: acorma@itq.upv.es; phone: +34963877800; fax: +349638 77809.

\section{Author Contributions}

The manuscript was written through contributions of all authors. All authors have given approval to the final version of the manuscript.

\section{Funding Sources}

Financial support by the Severo Ochoa program and Consolider-Ingenio 2010 (proyecto

MULTICAT) from MCIINN is acknowledged, and also to the King Saud University.

\section{ACKNOWLEDGMENT}

A. L.-P. thanks CSIC for a contract. J. O.-M. thanks ITQ for a postgraduate scholarship. J. R. C.A. and P. R.-M. thank MCIINN for the concession of a FPU contract.

\section{REFERENCES}

(1) Corma, A.; Leyva-Pérez, A.; Sabater, M. J. Chem. Rev. 2011, 111, 1657.

(2) Leyva-Pérez, A.; Corma, A. Angew. Chem., Int. Ed. 2012, 51, 64.

(3) Hashmi, A. S. K. Angew. Chem., Int. Ed. 2010, 49, 5232.

(4) a) Corma, A.; Juárez, R.; Boronat, M.; Sánchez, F.; Iglesias, M.; García, H. Chem. Commun. 2011, 47, 1446. b) Boronat, M.; Combita, D.; Concepción, P.; Corma, A.; 
García, H.; Juárez, R.; Laursen, S.; López-Castro, J. D. J. Phys. Chem. C 2012, 116, 24855. c) Daniel, M.-C.; Astruc, D. Chem. Rev. 2004, 104, 293.

(5) Grirrane, A.; Corma, A.; García, H. Science 2008, 322, 1661.

(6) González-Arellano, C.; Abad, A.; Corma, A.; García, H.; Iglesias, M.; Sánchez, F. Angew. Chem., Int. Ed. 2007, 46, 1536.

(7) Navalon, S.; Martin, R.; Alvaro, M.; Garcia, M. Angew. Chem., Int. Ed. 2010, 49, 8403.

(8) a) Kanuru, V. K.; Kyriakou, G.; Beaumont, S. K.; Papageorgiou, A. C.; Watson, D. J.; Lambert, R. M. J. Am. Chem. Soc. 2010, 132, 8081. b) Beaumont, S. K.; Kyriakou, G.; Lambert, R. M. J. Am. Chem. Soc. 2010, 132, 12246. c) Kyriakou, G.; Beaumont, S. K.; Humphrey, S. M.; Antonetti, C.; Lambert, R. M. ChemCatChem 2010, 2, 1444.

(9) Herzing, A. A.; Kiely, C. J.; Carley, A. F.; Landon, P.; Hutchings, G. J. Science 2008, $321,1331$.

(10) Hughes, M. D.; Xu, Y. J.; Jenkins, P.; McMorn, P.; Landon, P.; Enache, D. I.; Carley, A. F.; Attard, G. A.; Hutchings, G. J.; King, F.; Stitt, E. H.; Johnston, P.; Griffin, K.; Kiely, C. J. Nature 2005, 437, 1132.

(11) Toma, H. E.; Zamarion, V. M.; Toma, S. H.; Araki, K. J. Braz. Chem. Soc. 2010, 21, 1158.

(12) For reviews on the cyclotrimerisation reaction see a) Shaaban, M. R.; El-Sayed, R.; Elwahy, A. H. M. Tetrahedron 2011, 67, 6095. b) Kotha, S.; Brahmachary, E.; Lahiri, K. Eur. J. Org. Chem. 2005, 4741.

(13) The Stratakis' group has uncovered that $\mathrm{Au}-\mathrm{TiO}_{2}$ is an excellent catalyst for the disilylation of alkynes and isomerisation of epoxides, see a) Lykakis, I. N.; Psyllaki, A.; Stratakis, M. J. Am. Chem. Soc. 2011, 133, 10426. b) Raptis, C.; Garcia, H.; Stratakis, M. Angew. Chem., Int. Ed. 2009, 48, 3133.

(14) Das, A.; Dash, C.; Yousufuddin, M.; Celik, M. A.; Frenking, G.; Dias, H. V. R. Angew. Chem., Int. Ed. 2012, 51, 3940.

(15) Sá, J.; Goguet, A.; Taylor, S. F. R.; Tiruvalam, R.; Kiely, C. J.; Nachtegaal, M.; Hutchings, G. J.; Hardacre, C. Angew. Chem., Int. Ed. 2011, 50, 8912.

(16) a) Corma, A.; Serna, P.; Concepcion, P.; Calvino, J. J. J. Am. Chem. Soc. 2008, 130, 8748. b) Boronat, M.; Concepción, P.; Corma, A.; González, S.; Illas, F.; Serna, P. J. Am. Chem. Soc. 2007, 129, 16230. 
(17) a) Chirea, M.; Freitas, A.; Vasile, B. S.; Ghitulica, C.; Pereira, C. M.; Silva, F. Langmuir 2011, 27, 3906. b) Oliver-Meseguer, J.; Cabrero-Antonino, J. R.; Domínguez, I.; LeyvaPérez, A.; Corma, A. Science 2012, 338, 1452.

(18) Martin, R.; Menchon, C.; Apostolova, N.; Victor, V. M.; Alvaro, M.; Herance, J. R.; Garcia, H. ACS nano 2010, 4, 6957.

(19) Reported metal catalysts for the cyclotrimerisation reaction include cobalt, rhodium, ruthenium, titanium, molybdenum, and palladium, among others. See this and the following ref. for selected examples. These metals can perform the organometallic ring pathway. For cobalt see a) Agenet, N.; Gandon, V.; Vollhardt, K. P. C.; Malacria, M.; Aubert, C. J. Am. Chem. Soc. 2007, 129, 8860. b) Rhyoo, H.-Y.; Lee, B. Y.; Yu, H. K. B.; Chung, Y. K. J. Mol. Catal. 1994, 92, 41.

(20) For rhodium see Tanaka, K.; Toyoda, K.; Wada, A.; Shirasaka, K.; Hirano, M. Chem. Eur. J. 2005, 11, 1145.

(21) For ruthenium see Cadierno, V.; García-Garrido, S. E.; Gimeno, J. J. Am. Chem. Soc. 2006, 128, 15094, and ref. 22.

(22) Yamamoto, Y.; Arakawa, T.; Ogawa, R.; Itoh, K. J. Am. Chem. Soc. 2003, 125, 12143.

(23) For titanium see Ozerov, O. V.; Patrick, B. O.; Ladipo, F. T. J. Am. Chem. Soc. 2000, $122,6423$.

(24) For molybdenum see Ardizzoia, G. A.; Brenna, S.; LaMonica, G.; Maspero, A.; Masciocchi, N. J. Organometallic Chem. 2002, 649, 173.

(25) For palladium see Lin, Y.-Y.; Tsai, S.-C.; Yu, S. J. J. Org. Chem. 2008, 73, 4920, and ref. 26a.

(26) In the context of heterogeneous catalysis, palladium has shown good catalytic activity, see for instance Ormerod, R. M.; Lambert, R. M. J. Chem. Soc., Chem. Commun. 1990, 1421. We tested commercial Pd-carbon for the cyclotrimerisation of 1 under our standard conditions and an equimolecular product distribution 3a:3b was found after complete conversion of $\mathbf{1}$. This catalyst was also tested for the oxidative alkynylation of $\mathbf{1}$ and $\mathbf{2}$ and no product was found.

(27) a) Schwier, T.; Gevorgyan, V. Org. Lett. 2005, 7, 5191. b) García-Mota, M.; Cabello, N.; Maseras, F.; Echavarren, A. M.; Pérez-Ram írez, J.; Lopez, N. ChemPhysChem 2008, 9, 1624. 
(28) a) Shi, Z.; He, C. J. Org. Chem. 2004, 69, 3669. b) Reetz, M. T.; Sommer, K. Eur. J. Org. Chem. 2003, 3485.

(29) a) De Haro, T.; Nevado, C. J. Am. Chem. Soc. 2010, 132, 1512. b) For a recent review by the same authors on C-H activation by gold see De Haro, T.; Nevado, C. Synth. 2011, 16, 2530.

(30) a) For a recent review see Boronat, M.; Corma, A. J. Catal. 2011, 284, 138. b) Rodríguez, J. A.; Feria, L.; Jirsak, T.; Takahashi, Y.; Nakamura, K.; Illas, F. J. Am. Chem. Soc. 2010, 132, 3177. c) Boronat, M.; Corma, A. Dalton Trans. 2010, 39, 8538.

(31) a) Alves, L.; Ballesteros, B.; Boronat, M.; Cabrero-Antonino, J. R.; Concepción, P.; Corma, A.; Correa-Duarte, M. A.; Mendoza, E. J. Am. Chem. Soc. 2011, 133, 10251. b) Engle, K. M.; Mei, T.-S.; Wang, X.; Yu, J.-Q. Angew. Chem., Int. Ed. 2011, 50, 1478.

(32) Private communication from Prof. Doménech. For a recent related article see Doménech, A.; Leyva-Pérez, A.; Al-Resayes, S. I.; Corma, A. Electrochem. Commun. 2012, 19, 145.

(33) Leyva-Pérez, A.; Doménech, A.; Al-Resayes, S. I.; Corma, A. ACS Catal. 2012, 2, 121.

(34) Hodgson, D. M.; Talbot, E. P. A.; Clark, B. P. Org. Lett. 2011, 13, 5751.

(35) a) Weding, N.; Jackstell, R.; Jiao, H.; Spannenberg, A.; Hapke, M. Adv. Synth. Catal. 2011, 353, 3423. b) Zhang, W.; Sprafke, J. K.; Ma, M.; Tsui, E. Y.; Sydlik, S. A.; Rutledge, G. C.; Swager, T. M. J. Am. Chem. Soc. 2009, 131, 8446. 


\section{TOC graphic}

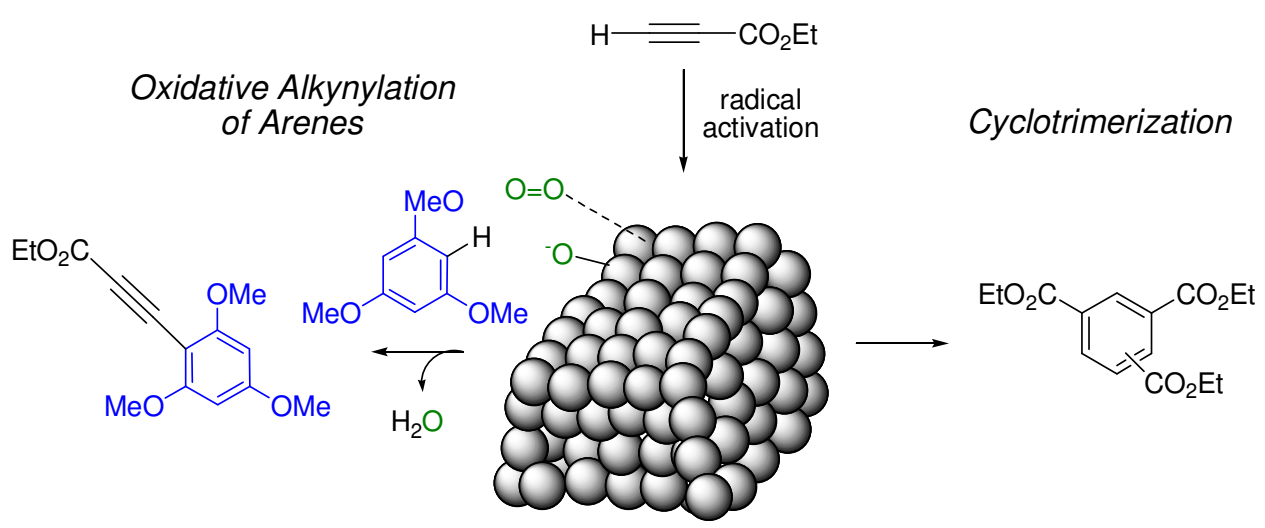

Gold Nanoparticles 